\title{
Variation of ionospheric slab thickness observations at Chumphon equatorial magnetic location
}

\author{
P. Kenpankho ${ }^{1}$, P. Supnithi ${ }^{1}$, T. Tsugawa ${ }^{2}$, and T. Maruyama ${ }^{2}$ \\ ${ }^{1}$ Faculty of Engineering, King Mongkut's Institute of Technology, Ladkrabang, Bangkok 10520, Thailand \\ ${ }^{2}$ Space Environment Group, National Institute of Information and Communications Technology, \\ Nukuikita, Koganei, Tokyo 184-8795, Japan
}

(Received June 9, 2010; Revised March 7, 2011; Accepted March 7, 2011; Online published June 14, 2011)

\begin{abstract}
This study presents the diurnal and seasonal variations of slab thickness at the equatorial magnetic latitudes in Thailand during 2004-2006, corresponding to the declining part of low solar activity. The GPS-derived total electron content (TEC) and the maximum electron density of the $F$-region $\left(N_{\mathrm{m}} F_{2}\right)$ are used to compute the slab thickness $(\tau)$ at the Chumphon station $\left(10.72^{\circ} \mathrm{N}, 99.37^{\circ} \mathrm{E}\right)$, located near the magnetic equator. The results show that large peaks of slab thickness exist during the pre-sunrise hours in all three seasons at Chumphon when compared with other latitudes. The maximum value of slab thickness occurs when the peak electron density in the $F_{2}$ region is at the lowest level. During daytime, the slab thickness ranges from 200 kilometers to 580 kilometers for all seasons. During nighttime, the maximum value of slab thickness is 1250 kilometers in the summer of 2004. Moreover, the diurnal variation shows two minima that appear around 0900 LT and 1900 LT, during the post-sunrise and sunset hours. The seasonal variations show that the average slab thickness daily value is greater during summer and winter than those during equinox. Our study finds that the slab thickness at Chumphon located near the equatorial latitude is much larger than those found at low, mid, and high latitudes. The difference in slab thickness between the equatorial latitude and other zones is explained by the lack of plasma flow from the plasmasphere to the $F_{2}$ region at the magnetic equator.
\end{abstract}

Key words: Ionospheric slab thickness, TEC, $N_{\mathrm{m}} F_{2}, f_{\mathrm{o}} F_{2}$, equatorial latitude, GPS TEC.

\section{Introduction}

Recent developments in satellite technology have resulted in the improvements in the observation of ionospheric variability. Measurements of the ionospheric total electron content (TEC) are useful for determining the delay of a radio signal transmitted from a global positioning system (GPS) satellite to a ground receiver (Goodwin et al., 1995). In this study, the diurnal, seasonal, and solar activity variations of the ionospheric slab thickness $(\tau)$ are investigated by using the GPS signals in the equatorial ionization anomaly (EIA) region.

Ionospheric slab thickness is defined as the ratio of TEC to the maximum electron density of the $F$-region $\left(N_{\mathrm{m}} F_{2}\right)$, proportional to the square of the $F_{2}$-layer critical frequency $\left(f_{\mathrm{o}} F_{2}\right)$. The ionospheric slab thickness is a significant parameter since it includes information regarding both the top and bottom sides of the ionosphere. Ionospheric slab thickness may also be regarded as the depth of an imaginary ionosphere that has the same TEC as the actual ionosphere and a uniform electron density that is equal to the maximum electron density of the actual ionosphere (Chuo, 2007). The study of slab thickness has been carried out by researchers (e.g., Bhonsle et al., 1965; Huang, 1983; Bhuyan et al., 1986; Davies and Liu, 1997; Gulyaeva et al., 2004; Jin et

Copyright (C) The Society of Geomagnetism and Earth, Planetary and Space Sciences (SGEPSS); The Seismological Society of Japan; The Volcanological Society of Japan; The Geodetic Society of Japan; The Japanese Society for Planetary Sciences; TERRAPUB.

doi:10.5047/eps.2011.03.003 al., 2007). They have found that the diurnal, seasonal, and solar activity variations of the slab thickness show significant dependence on the location of the observing station. During 1996-1999, corresponding to half of the 23rd solar cycle, the average daily value of the seasonal variations is greater during summer, and the reverse is true during equinox in the equatorial ionization anomaly (EIA) region. The slab thickness values are in general greater during the daytime (0800-1600 LT) and nighttime (2000-0400 LT) for summer and winter than other times. A significant systematic diurnal change of TEC, $N_{\mathrm{m}} F_{2}$, and slab thickness takes place at all seasons. The higher values of TEC and $N_{\mathrm{m}} F_{2}$ were observed during the equinoxes (semiannual anomaly) as well as in mid-daytime. Titheridge (1973) attributed the pre-sunrise peak in slab thickness to the downward movement of the ionosphere when the neutral winds that maintain the ionosphere decrease in velocity or reverse direction. The early morning peaks in slab thickness may appear due to the fact that sunrise is earlier at heights above the $F_{2}$-layer causing some production at the topside, tending to give TEC a lead over $N_{\mathrm{m}} F_{2}$ which is still decaying. For example, at low-latitude, the study indicates the occurrence of a pre-sunrise peak in the slab thickness at about 239-344 kilometers. At mid-latitude, the slab thickness is about 250-600 kilometers and at high-latitude, the slab thickness can reach 1100 kilometers during high solar activity (Iwamoto et al., 2002). In addition, Jayachandran et al. (2004) presented the slab thickness during the solar 
maximum and minimum phases of solar activity. Hourly values of TEC and $N_{\mathrm{m}} F_{2}$ at Hawaii (low-latitude), Boulder (mid-latitude), and Goosebay (high-latitude) are used in the study. This study shows that the variations of the slab thickness depend on the observing locations. From ionospheric height variations at the magnetic equator that are magnetic conjugate in the same magnetic meridian, it is possible to distinguish the electric field and meridional neutral wind effects with their polarity, transequatorial southward, northward, equatorward, or poleward (Maruyama, 1996).

Variations of TEC, $N_{\mathrm{m}} F_{2}$, and slab thickness parameters are presented in this paper. The data are obtained from Chumphon station, a part of the South East Asia Low Latitude Ionosphere Observation Network (SEALION) which is a joint project among the following institutions and countries: National Institute of Information and Communications Technology (NICT), Japan, King Mongkut's Institute of Technology Ladkrabang (KMITL), Thailand, Chiang Mai University (CMU), Thailand, National Institute of Aeronautics and Space (LAPAN), Indonesia, Hanoi Institute of Geophysics (HIG), Vietnamese Academy of Science and Technology, Vietnam, Center for Space Science and Applied Research (CSSAR), Chinese Academy of Sciences, China, and Kyoto University, Japan. These stations observe, monitor, and forecast the ionospheric variation in the Asia Pacific region near the magnetic equator. The measured data from 2004-2006 are analyzed based on the diurnal, monthly, and seasonal variations. Furthermore, the diurnal and seasonal variations of slab thickness at Chumphon are presented, discussed and compared with those observed at other latitudes.

\section{Observations and Methods}

The variation of slab thickness during the low solar activity period of 2004-2006 can be obtained from the relationship between TEC and $f_{\mathrm{o}} F_{2}$ values. The TEC data collected from the GPS receiver and $f_{\mathrm{o}} F_{2}$ are measured from the frequency modulated continuous wave (FMCW) ionosonde. Both parameters are from Chumphon, KMITL, located at longitude $99.30^{\circ} \mathrm{E}$ and latitude $10.70^{\circ} \mathrm{N}$, Thailand. The magnetic latitude for Chumphon station is $3.22^{\circ} \mathrm{N}$, close to the equatorial magnetic latitude. $N_{\mathrm{m}} F_{2}$ is the peak electron density in the $F_{2}$-region (electron $/ \mathrm{m}^{3}$ ), computed using the expression (Goodwin et al., 1995).

$$
N_{\mathrm{m}} F_{2}=1.24 \times 10^{10}\left(f_{\mathrm{o}} F_{2}\right)^{2},
$$

where $f_{\mathrm{o}} F_{2}$ is in $\mathrm{MHz}$, and $N_{\mathrm{m}} F_{2}$ in $\mathrm{m}^{-3}$. The $f_{\mathrm{o}} F_{2}$ is obtained from the ionograms recorded at a cadence of 15 minutes.

The TEC is the total electron content (\# of electrons $/ \mathrm{m}^{2}$ $=$ TECU) in a vertical column of $1 \mathrm{~m}^{2}$ cross-section (Goodwin et al., 1995) called a vertical TEC (VTEC). In the GPS system, every satellite transmits signals at two frequencies, $f_{1}=1575.42 \mathrm{MHz}$ and $f_{2}=1227.60 \mathrm{MHz}$. The GPS-TEC measurement system consists of a microstrip antenna, an amplifier, a TEC Meter, and a computer. The microstrip antenna type is right hand circularly polarized and receives two GPS signals with $f_{1}$ and $f_{2}$. The amplified signal from the amplifier is then sent to the Javad TEC Meter with embedded GPS receiver. The GPS receiver in TEC
Meter works when it continuously receives from 4 to 12 GPS signals that will lead to the computation of the slant TEC (STEC) values.

The STEC from a satellite to a receiver can be obtained from the difference between the pseudoranges $\left(P_{1}\right.$ and $\left.P_{2}\right)$, and the difference between the phases $L_{1}$ and $L_{2}$ of the two frequencies (Blewitt, 1990) shown as Eqs. (2) and (3)

$$
\begin{aligned}
\text { STEC } & =\frac{2\left(f_{1} f_{2}\right)^{2}}{k\left(f_{1}^{2}-f_{2}^{2}\right)}\left(P_{2}-P_{1}\right), \\
\text { STEC } & =\frac{2\left(f_{1} f_{2}\right)^{2}}{k\left(f_{1}^{2}-f_{2}^{2}\right)}\left(L_{1} \lambda_{1}-L_{2} \lambda_{2}\right),
\end{aligned}
$$

where $k$, related to the ionosphere refraction, is 80.62 $\left(\mathrm{m}^{3} / \mathrm{s}^{2}\right), \lambda_{1}$, and $\lambda_{2}$ are the wavelengths corresponding to $f_{1}$ and $f_{2}$, respectively.

The VTEC, in $1 / \mathrm{m}^{2}$, is computed from (Ma and Maruyama, 2003)

$$
\mathrm{VTEC}=\mathrm{STEC} \times \cos \chi .
$$

The zenith angle $\chi$ is given by

$$
\chi=\arcsin \left(\frac{R_{\mathrm{E}} \cos \alpha}{R_{\mathrm{E}}+h}\right),
$$

where $\alpha$ is the elevation angle of the satellite, $R_{\mathrm{E}}$ is the mean radius of the Earth, and $h$ is the height of the ionospheric layer, which is assumed as 400 kilometers.

In order to derive the absolute TEC, the satellite and receiver biases need to be included in Eq. (4) (Ma and Maruyama, 2003) as

$$
\mathrm{TEC}=\left(\mathrm{STEC}-b_{\mathrm{s}}-b_{\mathrm{r}}\right) \times \cos \chi,
$$

where $b_{\mathrm{s}}$ is the estimated satellite bias determined from GEONET, a GPS Earth Observation Network set up by the Geographical Survey Institute (GSI) of Japan, which has more than 1000 GPS receivers spreading over Japan (Miyazaki et al., 1997), $b_{\mathrm{r}}$ is the estimation of bias for a single receiver which is calculated based on the minimum standard deviation method (Ma and Maruyama, 2003).

TEC and $N_{\mathrm{m}} F_{2}$ can be used to compute the variation of slab thickness in kilometers (Goodwin et al., 1995). The slab thickness can be calculated as

$$
\tau=\frac{\mathrm{TEC}}{N_{\mathrm{m}} F_{2}}
$$

where TEC is in TECU and $N_{\mathrm{m}} F_{2}$ is in $1 / \mathrm{m}^{3}$.

The ionosondes continuously transmit radio waves from 2 to $30 \mathrm{MHz}$ and receive echoes from the ionosphere to provide the bottomside plasma density profile every $15 \mathrm{~min}$ utes. The data are automatically uploaded to KMITL in Bangkok to be analyzed. The observation parameters are summarized in (Saito and Maruyama, 2006). The diurnal and seasonal variations of slab thickness are investigated for the years 2004-2006. The period is divided into 3 seasons: equinox (March, April, September, and October), summer (May, June, July, and August), and winter (January, February, November, and December). 


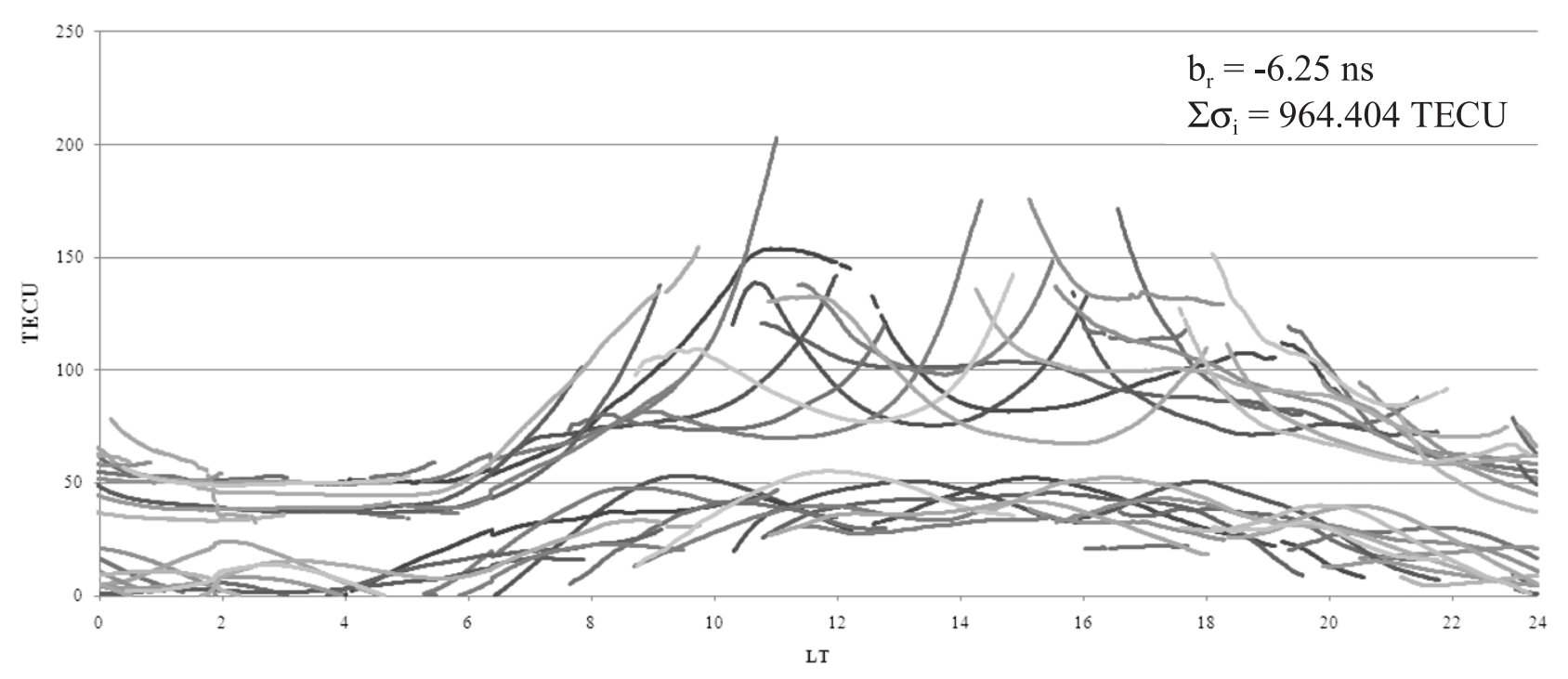

Fig. 1. The estimation of bias for a single receiver at Chumphon station, on January 1, 2004 (LT).
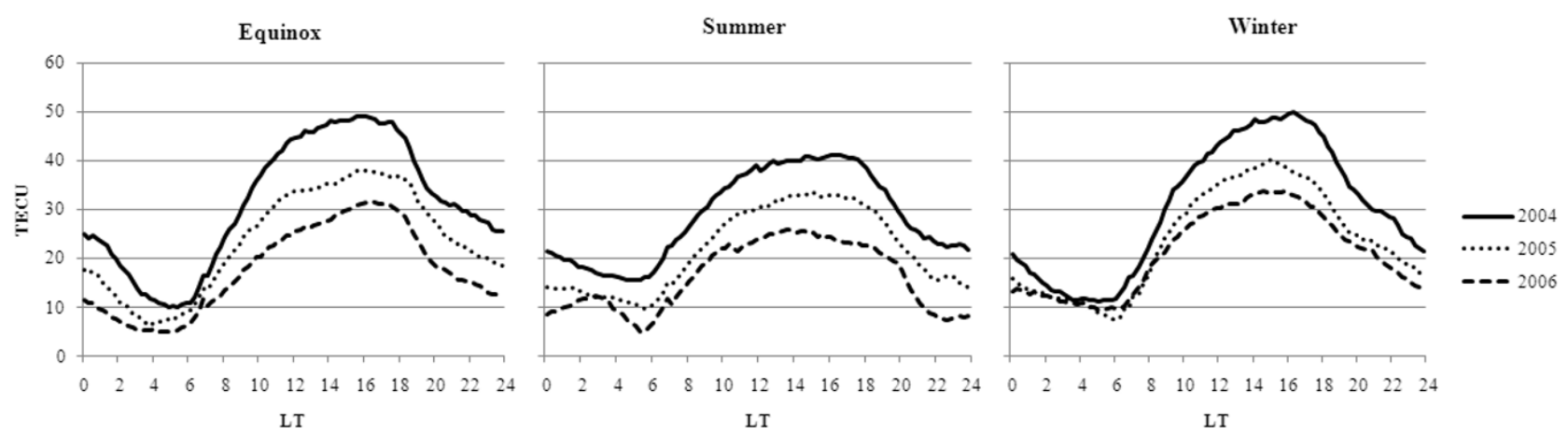

Fig. 2. Seasonal variations of GPS-TEC measurements at Chumphon station during 2004-2006 $\left(1 \mathrm{TECU}=10^{16} \mathrm{electrons} / \mathrm{m}^{2}\right)$.

\section{Analysis and Results}

\subsection{The variation of TEC}

Figure 1 shows an example of the STEC values at Chumphon station on January 1, 2004. The VTEC values can be obtained with the satellite and receiver biases accounted for. For a single receiver, the receiver bias is estimated to be $-6.25 \mathrm{~ns}$, giving the converged TEC curves with the minimum sum of standard deviation as shown in the bottom graphs of Fig. 1. We have tested the various receiver biases on the 5-day average of STEC and TEC values and found the receiver bias ranges between $-9.5 \mathrm{~ns}$ to $1.5 \mathrm{~ns}$.

Figure 2 shows the diurnal variation of monthly median values of GPS-TEC measurements for equinox, summer and winter seasons. The horizontal axis on each graph represents the hourly values at the local time, whereas the vertical axis on each graph shows the TEC values. It can be seen that for the diurnal variation behavior, TEC values decrease from year 2004 to 2006, with the maximum values occurring at daytime hours, and the minimum values occurring at nighttime hours. The maximum TEC values in the equinox and winter are higher than those in the summer during 2004-2006. The minimum values of TEC occur between 0300 LT and 0500 LT, while the maximum values occur between 1300 LT and 1800 LT. The peak occurrence around noontime has the largest values during the equinox and the lowest values for summer. The plots of the monthly median values of TEC against local time for Chumphon station for the period from 2004 to 2006 shows strong seasonal variations, with the largest daytime values occurring in winter of 2004 and the smallest values in summer of 2006.

Figure 3 shows the variation of the monthly median value of $N_{\mathrm{m}} F_{2}$ from 2004 to 2006. The $N_{\mathrm{m}} F_{2}$ values are directly calculated from $f_{\mathrm{o}} F_{2}$ following Eq. (1). It can be seen that the daytime values in 2004 are larger than those in 2005 and 2006. The minimum values occur in the winter of 2006 and the maximum values are in the equinox of 2004. The minimum value of $N_{\mathrm{m}} F_{2}$ occurs between 0400 LT and 0600 LT, the pre-sunrise hours in all seasons.

\subsection{Diurnal and seasonal variation of ionospheric slab thickness}

Figure 4 shows the diurnal variation of slab thickness for equinox, summer and winter seasons at Chumphon station from 2004 to 2006 . It can be seen that the diurnal variation of slab thickness pattern follows similar trends during these three years. During day time, the slab thickness ranges from 200 kilometers to 580 kilometers for all seasons. During nighttime, the maximum value of slab thickness is 1250 

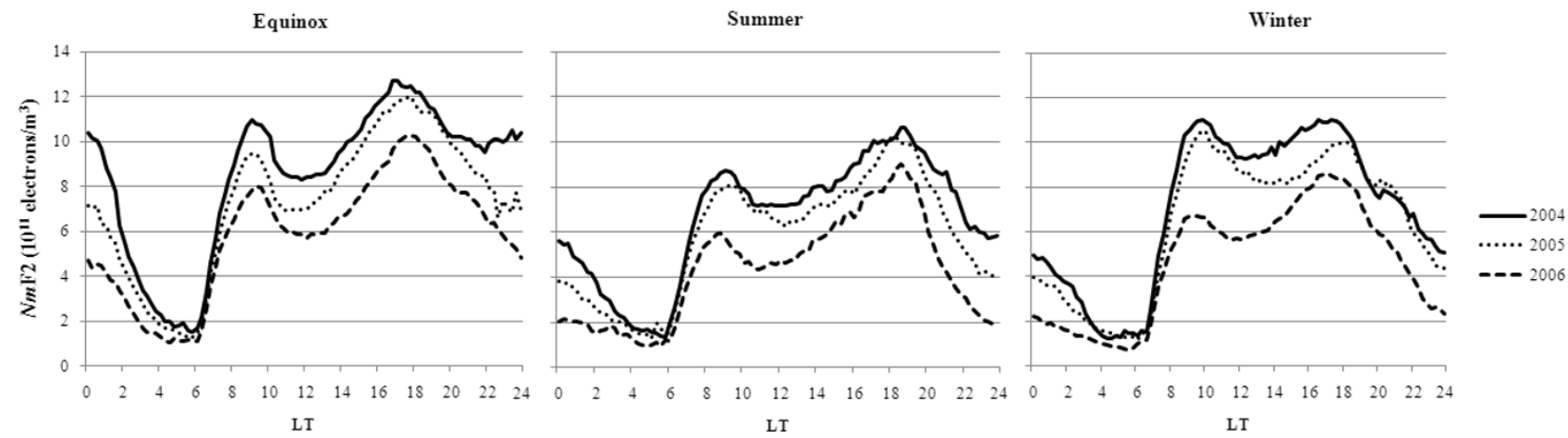

Fig. 3. Seasonal variations of $N_{\mathrm{m}} F_{2}$ results at Chumphon station during 2004-2006.
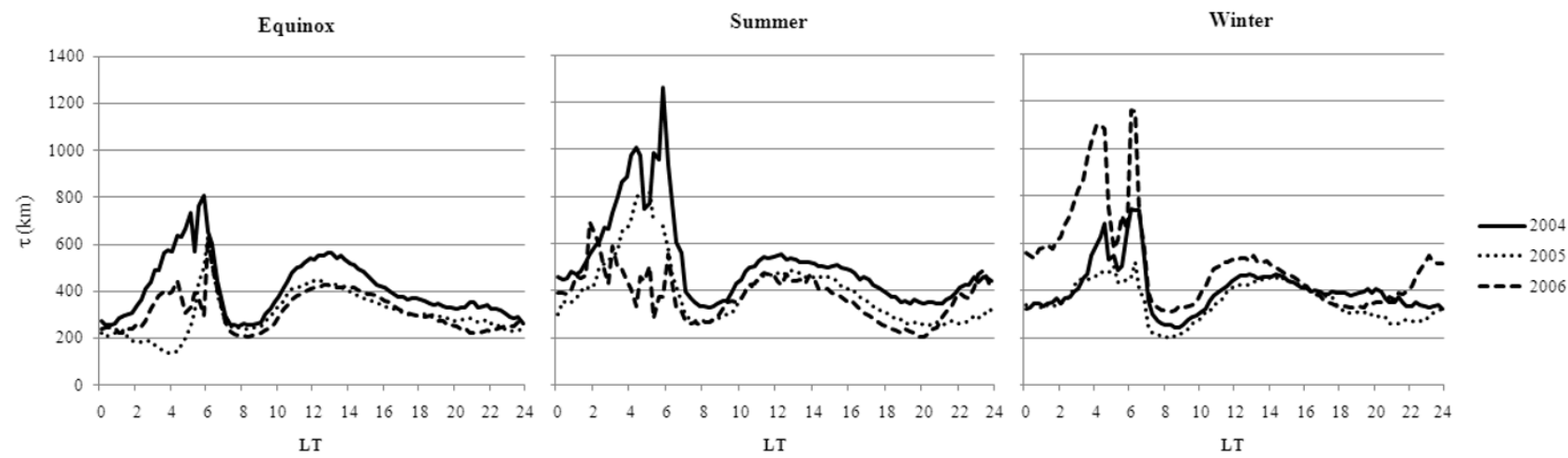

Fig. 4. Seasonal variations of slab thickness results at Chumphon station during 2004-2006.

kilometers for summer in 2004 with the maximum values occurring at pre-sunrise hours, and the minimum values occurring at nighttime hours. The maximum value of slab thickness occurs when the peak electron density in the $F_{2}$ region is at the lowest level. The diurnal variation shows abnormal peaks during 0300 LT-0500 LT, the pre-sunrise hours. Furthermore, the diurnal variation shows two minima at 0900 LT and 1900 LT, during the post-sunrise and sunset hours. The average daily slab thickness is greatest during summer and the lowest value is during equinox of 2005. In addition, the slab thickness values are greater during nighttime than those during daytime for all seasons. Among all three years, the average TEC is lower as the year goes up, due to the higher solar activity in 2004 than 2005 and 2006, respectively. For all seasons from 2004-2006, our study confirms the results of Jayachandran et al. (2004) for the slab thickness variation at low, mid, and high latitude.

\section{Comparisons}

We also compared slab thickness at Chumphon station in the equatorial latitude with Kokubunji station $\left(35.71^{\circ} \mathrm{N}\right.$, $\left.139.49^{\circ} \mathrm{E}\right)$ at mid latitude. The results from Chumphon and Kokubunji stations are shown during 2004 to 2006 on Fig. 5. In Fig. 5, the dotted line represents the slab thickness variation at Chumphon station and the solid line is for Kokubunji station. The $x$ axis represents for universal time (UT) and $y$ axis is for TECU at all seasons during 20042006. The local times at Kokubunji station leads those times for Chumphon at 2 hours. As the result, we find that the maximum slab thickness at Chumphon station is higher than that at Kokubunji station for summer during 20042006. During daytime, the lowest slab thickness variation is 200 kilometers at Chumphon station while the slab thickness variation reaches 1180 kilometers at Kokubunji station. However, during nighttime, the lowest slab thickness variation occurs at Kokubunji station but the highest slab thickness variation peaks, 1250 kilometers, at Chumphon station. In the equinox, the difference in the maximum slab thickness between Chumphon station and Kokubunji station is 200 kilometers. In the summer, the peak difference is as high as 850 kilometers, while, in the winter, this difference is about 450 kilometers.

Our study indicates that the slab thickness variation at the equatorial latitude of Chumphon location is about 200-580 kilometers during daytime for all seasons. However, at low latitude, the slab thickness variation is about 239-344 kilometers from Jayachandran et al. (2004) and about 160-300 kilometers studied by Gulyaeva et al. (2004). For mid latitude, the slab thickness variation is about 304-345 kilometers reported by Jayachandran et al. (2004) and about 153346 kilometers studied by Gulyaeva et al. (2004). Similarly, for high latitude, slab thickness variation is about 235-351 kilometers and 143-346 kilometers from Jayachandran et al. (2004) and Gulyaeva et al. (2004), respectively.

At the equatorial latitude of Chumphon station, the median diurnal variations of the seasonal slab thickness are at the highest levels during the summer. This result is also 

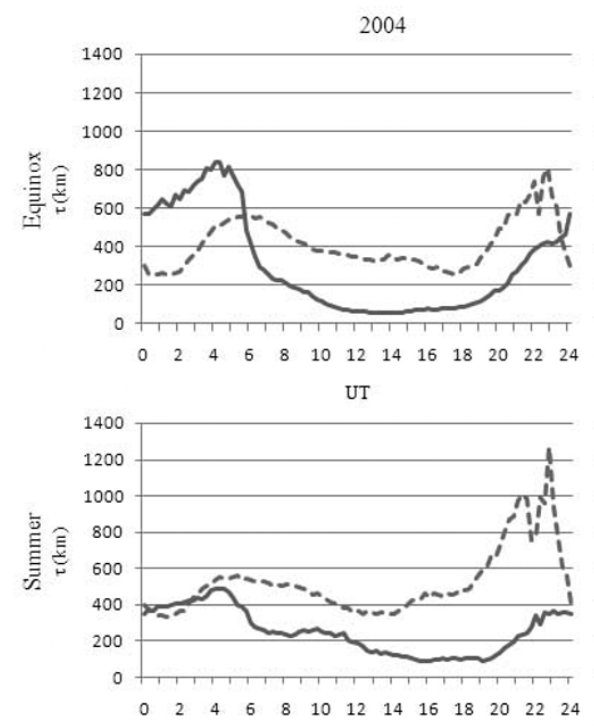

UT

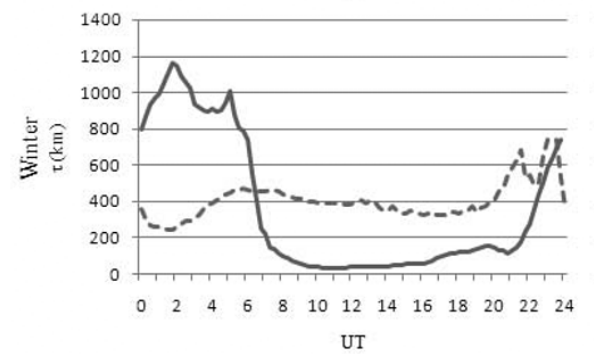

2005
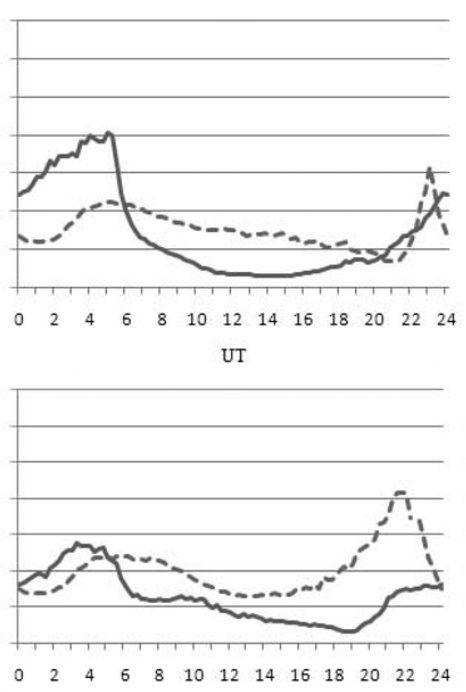

UT

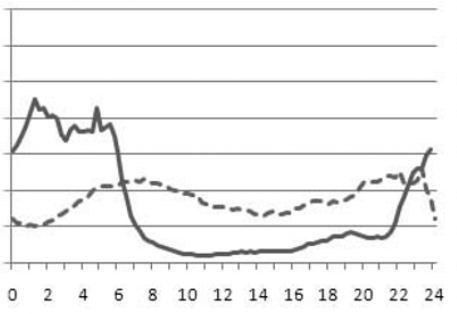

UT
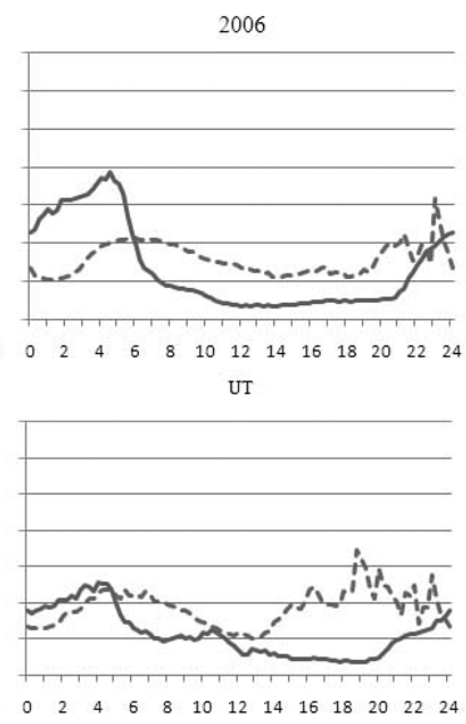

UT

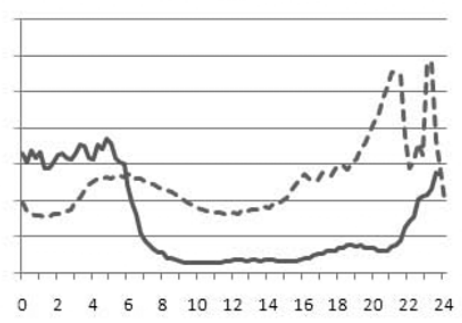

UT

Fig. 5. The variations of slab thickness at Chumphon (dashed line) and Kokubunji (solid line) during 2004-2006.

found by Chuo (2007) for low latitude and by Jayachandran et al. (2004) for mid-latitude and high latitude. However, Gulyaeva et al. (2004) shows that the highest values of slab thickness at low latitude are at equinox.

We found that the slab thickness at equatorial latitude can reach 1250 kilometers. On the other hand, the slab thickness at low and high latitude can reach 355 kilometers and 528 kilometers, respectively (Jayachandran et al., 2004). At mid latitude the slab thickness can reach 1100 kilometers (Iwamoto et al., 2002).

\section{Discussions}

Physical explanations for the observed variations in slab thickness can be given. The local minimum for $f_{\mathrm{o}} F_{2}$ around 1200 LT is caused by the strong eastward electric field and the resulting fountain effect. In general, lower TEC and $N_{\mathrm{m}} F_{2}$ in the summer as compared to other seasons are caused by atmospheric composition changes, generally referred to as the seasonal anomaly (Chuo, 2007). Higher $N_{\mathrm{m}} F_{2}$ values and smaller slab thickness in the equinox as compared to the other seasons around midnight are caused by the convergent wind toward the equator.

In contrast to the above, in summer and winter, the meridional wind, which is interhemispheric, blows off the bottomside plasma increasing the recombination. A large slab thickness around 0300 LT-0500 LT can be interpreted as follows: During the night, chemical recombination proceeds in the lower ionosphere. At mid latitudes, however, plasma is supplied from the plasmasphere along magnetic field lines. The equatorial ionosphere on the other hand is not connected to the plasmasphere by magnetic field lines, and therefore no plasma replenishment is provided.

The increase in $f_{\mathrm{o}} F_{2}$ and TEC with decreasing slab thickness indicates that TEC increases slower than $N_{\mathrm{m}} F_{2}$. It has been suggested that near the equator, the eastward horizontal electric fields of the atmospheric dynamo in the $E$-region were enhanced during the local daytime (Liu et al., 1999). The enhancement of the eastward electric fields increases the vertical $E \times B$ plasma drift to higher altitudes, and then diffuses it downward producing the enhanced concentration during daytime in the equatorial ionospheric anomaly region. Rishbeth et al. (1987) have suggested that thermospheric winds traveling toward the equator, which are driven by auroral heating, cause the atmospheric composition to changes such that there is a decrease in $f_{\mathrm{o}} F_{2}$ and TEC.

It is interesting to note that there is an abnormal peak $(1250 \mathrm{~km})$ in the slab thickness during the pre-sunrise period (0300 LT-0500 LT), particularly in summer and winter for all the solar phases. Two major factors are associated with this peak at pre-sunrise: electric field and zonal neutral wind. Woodman (1970) reports an enhanced vertical plasma drift before the sunrise in the $F$-region at Jicamarca. In addition, Krishna Murthy et al. (1990) have found that the meridian neutral wind turns southward at 0300 LT and reverses at 0500 LT for low latitude, and the southward neutral wind produces the $F$-layer uplift. Furthermore, Aggson 
et al. (1995) have reported a number of examples of anomalous enhancements of the eastward electric fields during the period close to sunrise in the equatorial ionospheric $F$ region by using the data obtained from an equatorial satellite. Titheridge (1973) has suggested that the pre-sunrise peak in the slab thickness is due to the downward movement of the ionosphere, when the neutral winds maintaining the ionosphere decrease or reverse. The post-sunset increase in the slab thickness observed during different seasons at low latitudes (Bhuyan et al., 1986) could be attributed to the equatorial pre-reversal enhancement caused by the occurrence of a post-sunset strong eastward electric field existing over equatorial latitudes (Fejer et al., 1979).

\section{Conclusion}

Daily, hourly and monthly median data of TEC and $f_{\mathrm{o}} F_{2}$ are obtained from Chumphon station, Thailand, located near the magnetic equator during 2004-2006. Those data are used for deriving and analyzing the diurnal, monthly, and seasonal variations of the slab thickness. Our study finds that slab thickness at Chumphon located near the equatorial latitude is much larger than those found at the low, mid, and high latitudes. The seasonal variations show that the greatest average slab thickness is during summer and the lowest value is during equinox. The diurnal variation shows abnormal peaks at 1250 kilometers during 0300 LT-0500 LT, the pre-sunrise hours in the summer of 2004. During daytime, the slab thickness ranges from 200 to 580 kilometers for all seasons. During nighttime, the value of slab thickness varies between 200 and 1250 kilometers. In addition, we investigate the slab thickness variation by making the comparison of slab thickness at Chumphon station in the equatorial latitude with Kokubunji station in the mid latitude during 2004-2006, corresponding to the decreasing part of low solar activity. We found that the maximum ionospheric slab thickness value at Kokubunji is higher than the maximum value at Kokubunji. The result confirms that the slab thickness at the equatorial latitude is larger than those found at mid latitude.

Acknowledgments. The authors are grateful to the National Institute of Information and Communications Technology (NICT), Japan, for the financial support and necessary equipment.

\section{References}

Aggson, T. L., F. A. Herrero, J. A. Johnson, R. F. Pfaff, H. Laakso, N. C. Maynard, and J. J. Moses, Satellite observation of zonal electric field near sunrise in equatorial ionosphere, J. Atmos. Terr. Phys., 57, 19-24, 1995.

Bhonsle, R. V., A. V. Da Rosa, and O. K. Garriott, Measurement of total electron content and equivalent slab thickness of the mid-latitude ionosphere, Radio Sc., 69D(7), 929, 1965.

Bhuyan, P. K., L. Singh, and T. R. Tyagi, Equivalent slab thickness of the ionosphere over $26^{\circ} \mathrm{N}$ through the ascending half of a solar cycle, Ann. Geophys., 4, 131, 1986.

Blewitt, G., An automatic editing algorithm for GPS data, Geophys. Res. Lett., 17, 199-202, 1990.

Chuo, Y. J., The variation of ionospheric slab thickness over equatorial ionization area crest region, J. Atmos. Sol.-Terr. Phys., 69, 947-954, 2007.

Davies, K. and X. M. Liu, Ionospheric slab thickness in middle and lowlatitudes, Radio Sci., 26(4), 997-1005, 1997.

Fejer, B. G., C. A. Gonzales, D. T. Farley, and M. C. Kelley, Equatorial electric fields during magnetically disturbed conditions: 1 . The effect of the interplanetary magnetic field, J. Geophys. Res., 84, 5797-5802, 1979.

Goodwin, G. L., J. H. Silby, K. J. Lynn, A. M. Breed, and E. A. Essex, GPS satellite measurements: ionospheric slab thickness and total electron content, J. Atmos. Sol.-Terr. Phys., 57(14), 1723-1732, 1995.

Gulyaeva, T. L., B. Jayachandran, and T. N. Krishnankutty, Latitudinal variation of ionospheric slab thickness, Adv. Space Res., 33, 862-865, 2004.

Huang, Y. N., Some result of ionospheric slab thickness observations at Lunping, J. Geophys. Res., 88, 5517, 1983.

Iwamoto, I., H. Katoh, T. Maruyama, H. Minakoshi, S. Watari, and K. Igarashi, Latitudinal variation of solar flux dependence in the topside plasma density: comparison between IRI model and observations, $A d v$. Space Res., 29(6), 877-882, 2002.

Jayachandran, B., T. N. Krishnankutty, and T. L. Gulyaeva, Climatology of ionospheric slab thickness, Ann. Geophys., 22, 25-33, 2004.

Jin, S., J. Cho, and J. Park, Ionospheric slab thickness and its seasonal variations observed by GPS, J. Atmos. Sol.-Terr. Phys., 69, 1864-1870, 2007.

Krishna Murthy, B. K., S. S. Hari, and V. V. Somayajulu, Nighttime equatorial thermospheric meridional winds from ionospheric $\mathrm{h}^{\prime} \mathrm{F}$ data, $J$. Geophys. Res., 95, 4307-4310, 1990.

Liu, J. Y., H. F. Tsai, C. C. Wu, C. L. Tseng, L. C. Tsai, W. H. Tsai, K. Liou, and J. K. Chao, The effect of geomagnetic storm on ionospheric total electron content at the equatorial anomaly region, Adv. Space Res., 24(11), 1491-1494, 1999.

Ma, G. and T. Maruyama, Derivation of TEC and estimation of instrumental biases from GEONET in Japan, Ann. Geophys., 21, 2083-2093, 2003.

Maruyama, T., Modeling study of equatorial ionospheric height and spread F occurrence, J. Geophys. Res., 101, 5157-5163, 1996.

Miyazaki, S., T. Saito, M. Sasaki, Y. Hatanaka, and Y. Iimura, Expansion of GSI's nationwide GPS array, Bull. Geogr. Surv. Inst., 43, 23-34, 1997.

Rishbeth, H., T. J. Fuller-Rowell, and D. Rees, Diffusive equilibrium and vertical motion in the thermosphere during a severe magnetic storm: a computational study, Planet. Space Sci., 35, 1157-1165, 1987.

Saito, S. and T. Maruyama, Ionospheric height variations observed by ionosondes along magnetic meridian and plasma bubble onsets, Ann. Geophys., 24, 2991-2996, 2006.

Titheridge, J. E., The slab thickness of the mid-latitude Ionosphere, Planet. Space Sci., 1, 1125, 1973.

Woodman, R. F., Vertical velocities and east-west electric fields at the magnetic equator, J. Geophys. Res., 75, 6249-6259, 1970.

P. Kenpankho (e-mail: kkpraser@kmitl.ac.th), P. Supnithi, T. Tsugawa, and T. Maruyama 